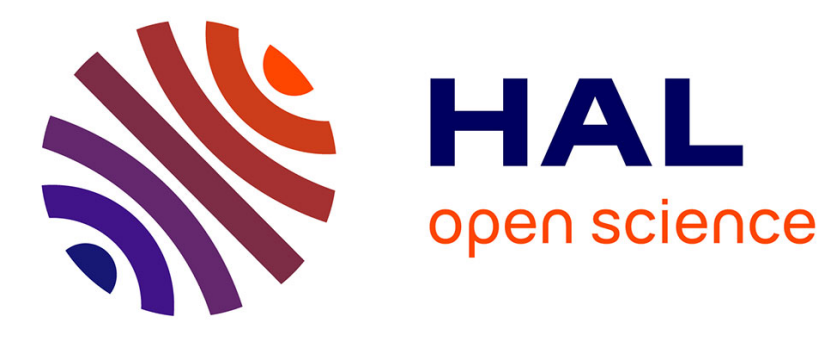

\title{
Probing the organization of fulvic acid using a cationic surfactant
}

\author{
Abdul Amir Chaaban, Bruno Lartiges, Véronique Kazpard, Celia \\ Plisson-Chastang, Laurent Michot, Isabelle Bihannic, Céline Caillet, \\ Benedicte Prelot
}

\section{To cite this version:}

Abdul Amir Chaaban, Bruno Lartiges, Véronique Kazpard, Celia Plisson-Chastang, Laurent Michot, et al.. Probing the organization of fulvic acid using a cationic surfactant. Colloids and Surfaces A: Physicochemical and Engineering Aspects, 2016, 504, pp.252-259. 10.1016/j.colsurfa.2016.05.032 . hal-02135192

\section{HAL Id: hal-02135192 \\ https://hal.science/hal-02135192}

Submitted on 21 May 2019

HAL is a multi-disciplinary open access archive for the deposit and dissemination of scientific research documents, whether they are published or not. The documents may come from teaching and research institutions in France or abroad, or from public or private research centers.
L'archive ouverte pluridisciplinaire HAL, est destinée au dépôt et à la diffusion de documents scientifiques de niveau recherche, publiés ou non, émanant des établissements d'enseignement et de recherche français ou étrangers, des laboratoires publics ou privés. 
1 Published in Colloids and Surfaces A: Physicochem. Eng. Aspects 504(2016) 252-259

2 http://dx.doi.org/10.1016/j.colsurfa.2016.05.032

3

4 Probing the organization of fulvic acid using a cationic surfactant

5

6 Abdul Amir CHAABAN ${ }^{\mathrm{a}, \mathrm{b}^{*}}$, Bruno LARTIGES ${ }^{\mathrm{a}^{*}}$, Veronique KAZPARD $^{\mathrm{b}}$, Celia

7 PLISSON-CHASTANG ${ }^{\mathrm{c}}$, Laurent MICHOT ${ }^{\mathrm{d}}$, Isabelle BIHANNIC ${ }^{\mathrm{e}}$, Celine

8 CAILLET $^{\mathrm{e}}$, Benedicte PRELOT ${ }^{\mathrm{f}}$

9

${ }^{\mathrm{a}}$ University of Toulouse (Paul Sabatier), Geosciences Environnement Toulouse (UMR

CNRS-UPS-IRD), 14 Av. E. Belin, 31400 Toulouse, France.

$12{ }^{\mathrm{b}}$ Lebanese University, Plateforme de Recherche et d'Analyses en Sciences des

13 l'Environnement (PRASE-EDST), Campus Hadath, Lebanon.

$14{ }^{\mathrm{c}}$ University of Toulouse (Paul Sabatier), Laboratoire de Biologie Moléculaire

15 Eucaryote (UMR CNRS-UPS 5099), 31400 Toulouse, France.

$16{ }^{\mathrm{d}}$ University Pierre et Marie Curie, Laboratoire PHENIX (UMR 8234), 4 Place Jussieu, 1772522 Paris Cedex 5, France.

$18{ }^{\mathrm{e}}$ University of Lorraine, LIEC (Laboratoire Interdisciplinaire des Environnements

19 Continentaux), UMR CNRS 7360, 54501 Vandoeuvre-les-Nancy, France.

$20{ }^{\mathrm{f}}$ University of Montpellier II, 2 Place E. Bataillon, ICGM (AIME), 34095 Montpellier 21 Cedex 5, France.

23 E-mail addresses:

24 Abdul Amir CHAABAN: abdulamirshaban@hotmail.com 
25 Bruno LARTIGES: bruno.lartiges@get.obs-mip.fr

26 Veronique KAZPARD: kveronique@ul.edu.lb

27 Celia PLISSON-CHASTANG: celia.plisson-chastang@ibcg.biotoul.fr

28 Laurent MICHOT: laurent.michot@upmc.fr

29 Isabelle BIHANNIC: isabelle.bihannic@univ-lorraine.fr

30 Celine CAILLET: celine.caillet@univ-lorraine.fr

31 Benedicte PRELOT: benedicte.prelot@um2.fr)

32

*Corresponding authors: Abdul-Amir CHAABAN

34

35

36

37

38

39

40
Tel: +33684016703

E-mail: abdulamirshaban@hotmail.com

and

Bruno LARTIGES

Tel: +33630063405

E-mail: bruno.lartiges@get.obs-mip.fr 


\section{Abstract}

The organization of Suwannee River Fulvic Acid (SRFA) is investigated through the interaction of SRFA with a cationic surfactant molecule (Dodecyl-trimethylammonium chloride (DTAC)). Turbidity measurements, Dynamic light scattering, electrophoretic mobility, surface tension, and cryo-transmission electron microscopy are combined to describe the SRFA/DTAC molecular structures thus obtained. Increasing DTAC concentration, fulvic acid-rich unilamellar vesicles, globules, aggregates of globules, disks, DTAC-rich unilamellar vesicles, and loosely aggregated spheroidal structures, are successively observed. Such sequence of molecular structures is typically found in phase diagrams of catanionic systems (mixture of oppositely charged surfactants). The strong surface activity of fulvic acid/DTAC complexes and the geometrical constraints associated with the formation of vesicles imply that a major component of SRFA is an individual amphiphile negatively charged of molecular size similar to that of DTAC. This soft matter approach supports a supramolecular organization for SRFA.

Keywords: Suwannee River Fulvic Acid, cationic surfactant, supramolecular organization, catanionic systems, cryo-transmission electron microscopy.

\section{Introduction}

Humic substances (HS), operationally classified according to their solubility into fulvic acid, humic acid, and humin, are ubiquitous organic compounds in soils and aquatic systems [1]. They are formed from the by-products of organic material degradation (e.g. 
plant debris, microorganisms) but also in part from the condensation of small organic molecules [2][3][4][5]. Besides their obvious role in carbon geocycling, HS have been shown to be key components in the transport/sequestration of xenobiotics and metal contaminants in the environment [6][7].

Extensive characterization of HS revealed that those compounds not only contain a large proportion of carboxylic and phenolic groups that make them hydrophilic, but also aliphatic moieties that give them surface active and hydrophobic-binding properties [8][9]. A characteristic size scale of HS determined by various techniques is about 1-2.5 $\mathrm{nm}[10][11][12][13][14][15]$. Changes in solution $\mathrm{pH}$, adsorption experiments and complexation experiments with polycations, have revealed the flexibility of HS structure $[16][17][18][19][20]$. Furthermore, modelling of their charge characteristics suggests that HS can be regarded as soft and porous structures [21].

Still, the detailed organization of HS remains a matter of debate: molecular weight measurements performed at different stages of extensive fractionation schemes suggest that HS can be regarded as macromolecules or slightly branched polymers that can coil or adopt an extended conformation according to solution properties [1][22][23][24], whereas some Size Exclusion Chromatography experiments and NMR results suggest that HS correspond to supramolecular associations of small heterogeneous molecules that can be disrupted in the presence of organic acids [6][10][25][71][72][73]. To account for the surface-active properties of HS and the enhanced solubility of hydrophobic organic compounds in their presence [26], such molecular aggregates have also been described as micelles with a hydrophilic exterior and a hydrophobic core [9]. 
89 A-middle-of-the-road view has also been taken, the fulvic fraction being identified as a supramolecular assembly, and the humic fraction corresponding to the coexistence of both macromolecular and supramolecular patterns [27].

The main goal of the present paper is to assess which of the two structural concepts, polymeric or supramolecular, is the more appropriate for Suwanee river fulvic acid (SRFA), a reference organic material provided by IHSS. For that purpose, we investigate the association between SRFA and various concentrations of Dodecyltrimethylammonium chloride (DTAC), a cationic surfactant molecule. Adding an oppositely charged amphiphilic molecule to SRFA is expected to induce drastic restructurations of the fulvic colloid driven by both electrostatic and hydrophobic interactions. Previous works followed a similar strategy by exploring the structure of humate/alkylammonium chloride precipitates using X-ray diffraction [28] and SmallAngle X-ray Scattering [29], whereas most other studies dealing with the association of a surfactant with humic substances were carried out in the context of contaminant transport in the environment, and focused on the binding of the detergent to humic colloids [30][31][32][33].

The various molecular structures formed upon addition of DTAC to a SRFA suspension are investigated using turbidity and Dynamic Light Scattering (DLS) measurements that provide a rapid assessment of complex formation, electrophoretic mobility and surface tension measurements that yield information about the extent of neutralization and surface active properties of SRFA/DTAC complexes, and Cryogenic Transmission Electron Microscopy (Cryo-TEM) that directly images those complexes. We show that 
such soft matter approach provides additional tools to assess the organization of humic substances.

\section{Experimental Section}

\subsection{Materials}

Suwannee River Fulvic acid (SRFA) was obtained from the International Humic Substances Society (IHSS) (Fulvic Acid Standard 2S101F). SRFA is extracted from the Suwannee river, a blackwater river that flows from the Okefenokee Swamp (Georgia), characterized by a $\mathrm{pH}$ of 4 and a Dissolved Organic Carbon (DOC) content ranging from 25 to $75 \mathrm{mg} / \mathrm{L}$ [34]. Dodecyltrimethyl ammonium chloride $\left(\mathrm{C}_{15} \mathrm{H}_{34} \mathrm{ClN}\right.$ - DTAC) was purchased from Sigma-Aldrich (purity 99\%). With a Krafft temperature below 0 ${ }^{\circ} \mathrm{C}$, DTAC is readily soluble in water at ambient temperature [35][36] and its critical micelle concentration (CMC) at $30{ }^{\circ} \mathrm{C}$ is $21.7 \mathrm{mmol} / / \mathrm{L}$ [37]. Both fulvic acid and surfactant were used without further purification.

\subsection{Sample preparation}

The DTAC stock solution was prepared at $10 \mathrm{~g} / \mathrm{L}$ in deionised water (Millipore-MilliQ

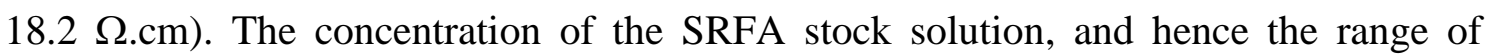
DTAC concentrations, were adapted to the technique of investigation. For Turbidity, Dynamic Light Scattering, Surface Tension and Electrophoretic Mobility measurements, a SRFA suspension of $20 \mathrm{mg} / \mathrm{L}$, i.e. $12 \mathrm{mg} \mathrm{C} / \mathrm{L}$, was prepared by adding 
the appropriate mass of fulvic acid into $500 \mathrm{~mL}$ of deionised water. For Cryo-TEM, stock suspensions of $20 \mathrm{mg} / \mathrm{L}$ and $1 \mathrm{~g} / \mathrm{L}$ were used. The SRFA stock solutions were prepared daily and mechanically mixed overnight in the dark to obtain a well-dispersed suspension. The dissolved organic carbon was checked for each prepared stock solution (Shimadzu TOC-Vcsn).

SRFA/DTAC complexes were prepared by adding aliquots of the surfactant stock solution to $10 \mathrm{~mL}$ of SRFA suspension and by submitting the mixture to gentle overhead agitation (3 times). Both DTAC and fulvic acid stock solutions as well as SRFA/DTAC samples were maintained at $30^{\circ} \mathrm{C}$ in a heating bath during the experiments, i.e. a temperature at which the alkyl chain of the surfactant is flexible.

\subsection{Characterization of SRFA/DTAC complexes}

The turbidity of SRFA/DTAC suspensions was measured as a function of time using a HACH LANGE 2100Q turbidimeter. Conductivity and pH (WTW Multiline F/SET), surface tension (KRUSS K12 Processor Tensiometer using a Wilhelmy plate), the electrophoretic mobility and the size of the fulvic acid-surfactant aggregates (Malvern Zetasizer Nano ZS) were measured at the end of the experiment.

Cryo-TEM observations were carried out at the Multiscale Electron Imaging (METI) platform at the University of Toulouse using a JEOL 2100 Lab6 transmission electron microscope equipped with a Gatan 626 cryoTEM grids holder. Images were recorded with a Gatan ultrascan1000 camera under low dose conditions (about 10 electrons per 
$161 \AA^{2}$ ). $4 \mu \mathrm{L}$ of SRFA/DTAC suspension was deposited onto a LACEY/CARBON FILM 162 grid previously ionized using PELCO-easi Glow 91000 glow discharging-cleaning

163

164 system. After blotting for 0.2 second to remove the excess added volume (Leica EM GP controlled vitrification system at $30{ }^{\circ} \mathrm{C}$ and $85 \%$ relative humidity), the grid was immediately plunged into liquid ethane at its freezing point $-185{ }^{\circ} \mathrm{C}$ and then stored in liquid nitrogen. The size distribution of SRFA/DTAC complexes was obtained by counting the aggregates in logarithmically spaced size bins such that $d_{i+1}=2^{1 / 3} d_{i}$, which yields equally spaced size intervals on a x-axis log scale [38]. The mean aggregate size D was calculated from:

$$
D=\sum_{i=1}^{i=k} n_{i} D_{i} / \sum_{i=1}^{i=k} n_{i}
$$

where $n_{i}$ is the number of aggregates measured in range i, $D_{i}$ is the middle of class range, and $k$ is the total number of bins.

\section{RESULTS}

\subsection{Turbidity Measurements}

Figure 1 shows the temporal evolution of the turbidity of SRFA/DTAC mixtures obtained after various DTAC additions to a $20 \mathrm{mg} / \mathrm{L}$ fulvic acid suspension at natural $\mathrm{pH}$ (4.32). At low and high DTAC concentration, the turbidity increases to reach a plateau after about 25 minutes, whereas in the $2.8-4.7 \mathrm{mmol} / \mathrm{L}$ range, the turbidity evolution is characterized by a rapid early overshoot followed by a slow stabilizing 
trend. For all surfactant additions, the $\mathrm{pH}$ of the SRFA/DTAC mixtures remains close to that of the initial fulvic acid solution (figure S1 in Supporting Information).

At steady-state, i.e. after about two hours, the variation of turbidity with DTAC concentration is characterized by two well-defined peaks (fig. 2a). Such variation may be the result of SRFA/DTAC interactions but, as DTAC is a salt, could also be related to a change in solution ionic strength. As illustrated in figure 2, substituting either $\mathrm{NaCl}$ or the analogous surfactant of shorter alkyl chain Octyltrimethylammonium chloride (OTAC) to DTAC, led to an equivalent linear increase in solution conductivity without any change in the turbidity of SRFA suspensions. Therefore, the main features of the SRFA/DTAC turbidity curve should be predominantly explained by the association of SRFA with both oppositely-charged polar head groups and hydrophobic alkyl chains of DTAC.

\subsection{Electrophoretic mobility, DLS and Surface Tension measurements}

Figure 3 shows the electrophoretic mobility and the particle size of SRFA/DTAC complexes as a function of surfactant concentration. In each graph, the turbidity curve is superimposed for comparison. Unexpectedly, at low DTAC concentration, the electrophoretic mobility becomes more negative upon the addition of cationic surfactant to reach a minimum that coincides with the first turbidity peak. The electrophoretic mobility then increases to reach positive values above $3.5 \mathrm{mmol} / \mathrm{L}$, and finally stabilizes in the decreasing part of the second turbidity peak. The opposite patterns followed by turbidity and electrophoretic mobility curves imply a significant reorganization of the 
fulvic colloid since new negatively charged sites have become electrokinetically-active during the charge neutralization of the anionic functional groups of fulvic acid with DTAC. Such result is consistent with Duval et al. [21] view of humic substances as permeable and flexible structures, the neutralization of SRFA "external" sites by the surfactant turning the fulvic structure inside out and exposing "internal" ionogenic sites. On the other hand, the lack of correlation between those same curves in the concentration range of the second aggregation peak suggests an association between DTAC and SRFA essentially driven by hydrophobic interactions in the presence of excess surfactant. Those hydrophobic interactions may originate either from previously hidden hydrophobic moieties displayed by the reorganization of SRFA, or from the hydrophobicity of SRFA/DTAC complexes that facilitates the sorption of supplementary surfactant molecules.

The particle size measured by DLS at $2 \mathrm{~h}$ remains in the $80-130 \mathrm{~nm}$ range at the start of the first turbidity peak, reaches a maximum in the valley between the two turbidity peaks when neutral SRFA/DTAC complexes are formed, and then decreases substantially to stabilize around $150 \mathrm{~nm}$ in the DTAC concentration range of the second turbidity peak (fig. 3b). Such behaviour implies that the two increases in turbidity correspond to the formation of an increased number of individual entities rather than the formation of aggregated structures, which actually occurs around a DTAC concentration of $3.5 \mathrm{mmol} / \mathrm{L}$ in the valley between the turbidity peaks. All DLS plots exhibited a monomodal size distribution except at a DTAC concentration of $0.19 \mathrm{mmol} / \mathrm{L}$ where two populations centered on $16 \mathrm{~nm}$ and $80 \mathrm{~nm}$ were detected (inset of fig. $3 \mathrm{~b}$ ). 
230 According to Ritchie and Perdue [39], the potentiometric proton titration of SRFA (0.36 $\mathrm{g}$ in $\mathrm{NaCl} 0.1 \mathrm{M}$ ) yields an acidity of $6.44 \mathrm{meq} / \mathrm{g}$ Carbon at $\mathrm{pH} 4.2$. This should correspond to an initial charge of our fulvic acid solution of less than 0.077 meq (Dissolved organic carbon of $12 \mathrm{mgC} / \mathrm{L}$ ), which then implies that most of the added surfactant remains in solution when neutral SRFA/DTAC complexes are obtained. Such result is consistent with the adsorption isotherms reported in the literature for similar cationic C12-surfactant/fulvic acid systems [33].

Figure 4 shows that the surface tension is drastically reduced at very low DTAC concentration, and then further diminishes gradually in successive small steps corresponding to the concentration range of turbidity peaks and the valley in between. This reveals that fulvic acid/DTAC complexes are highly surface active, since values around $40 \mathrm{~mJ} / \mathrm{m}^{2}$ are only attained around CMC with pure DTAC [40]. Such effect, already noted by Gamboa and Olea [32], is reminiscent of the strong cooperative effect observed between oppositely charged surfactants at the air-water interface [41].

\subsection{Cryo-TEM observations}

CryoTEM observations performed with $20 \mathrm{mg} / \mathrm{L}$ SRFA suspensions at DTAC concentrations of $1.8 \mathrm{mmol} / \mathrm{L}$ and $7.58 \mathrm{mmol} / \mathrm{L}$, allow the identification of SRFA/DTAC molecular structures that make up the turbidity peaks. As illustrated in figure 5, poorly formed unilamellar vesicles and spongy networks are formed at those DTAC concentrations. The term vesicle is used here to describe the general vesicularlike architecture and in no way implies that the wall of the vesicle is made from a lipid 
bilayer. It is worth noting that the size of vesicles is comparable with that of the minor population at $16 \mathrm{~nm}$ detected by DLS. From the electrophoretic mobility measurements, it appears that the fulvic-rich vesicles formed at low DTAC concentration are negatively charged whereas the DTAC-rich vesicles obtained at higher surfactant concentration are positively charged.

Further cryo-TEM experiments conducted with a SRFA concentration of $1 \mathrm{~g} / \mathrm{L}$ provide a more complete picture of the interaction of fulvic acid with DTAC. At $1 \mathrm{~g} / \mathrm{L}$, the $\mathrm{pH}$ of the SRFA suspension is 2.95 , hence the charge of fulvic acid is smaller, and the DTAC concentration range that destabilizes SRFA is much lower. Figure 6 presents the various molecular structures obtained upon mixing SRFA with various DTAC concentrations. Unlike DTAC solutions that yield featureless micrographs (see figure S2 of the supporting information), the reference fulvic acid suspension (fig. 6a), i.e. $0 \mathrm{mmol} / \mathrm{L}$ DTAC, exhibits globular structures about $25-32 \mathrm{~nm}$ in diameter, as well as small aggregates of those globules (inset of fig. 6a). The size range obtained for the individual globules is in good agreement with previous SANS measurements performed with fulvic and humic acids in similar conditions (pH 5 and about $3 \mathrm{~g} / \mathrm{L}$ concentration) [42]. Smaller values of radii-of-gyration have been reported for SRFA at higher pHs, which suggests that the globular structures correspond to aggregates of SRFA [43][44][45]. Addition of $7.610^{-3} \mathrm{mmol} / \mathrm{L}$ of DTAC leads to the formation of unilamellar vesicles, both complete and open, mostly in the $12-20 \mathrm{~nm}$ range (fig. $6 \mathrm{~b} 1$ and $6 \mathrm{~b} 2$ ), as well as sparse spongy networks with budding vesicles attached on the branches (fig. $6 \mathrm{~b} 3$ and 6b4). Further addition of cationic surfactant, i.e. $3.0310^{-2} \mathrm{mmol} / \mathrm{L}$, increases the average size of the vesicles $(30.3 \mathrm{~nm})$ that now coexist with globular structures of similar size 
and aggregates of those globules (inset of fig. 6c). At a DTAC concentration of $5.6710^{-}$ ${ }^{2} \mathrm{mmol} / \mathrm{L}$, the unilamellar vesicles can no longer be identified and only merging aggregates of globules are found (fig. 6d).

Another kind of morphology, i.e. aggregates of disk-like structures, is observed after 45 minutes at a surfactant concentration of $7.5610^{-2} \mathrm{mmol} / \mathrm{L}$ (fig. 6e1). At longer times (101 min), cryo-TEM examination reveals that the platelets become larger and that they tend to adopt a hexagonal shape implying a well-defined local structure (fig. 6e2). When the surfactant concentration is further increased $\left(18.810^{-2} \mathrm{mmol} / \mathrm{L}\right)$, unilamellar vesicles (mean size around $19 \mathrm{~nm}$ ) are again spontaneously formed (fig. 6f1 and 6f2). As for the $20 \mathrm{mg} / \mathrm{L}$ SRFA concentration, those vesicles are generally closed and more abundant than at lower DTAC concentration. Less developed spongy-like networks with nascent vesicles are also frequently observed (fig. $6 \mathrm{f} 3$ and $6 \mathrm{f} 4$ ). Finally, at the highest surfactant concentration investigated $\left(74.310^{-2} \mathrm{mmol} / \mathrm{L}\right)$, loosely aggregated spheroidal structures $(\sim 22.8 \mathrm{~nm})$ are found (fig. $6 \mathrm{~g})$.

The size histograms of SRFA/DTAC complexes observed by cryo-TEM and the evolution of their mean diameter as a function of surfactant concentration are shown in figure S3 (Supporting Information). All distributions are monomodal with a slight skewness towards larger sizes when an aggregation phenomenon has been detected on the micrographs. In those cases, the size distributions are certainly biased because the large aggregates can be drained away during the blotting step of sample preparation [46]. 
302

303

304

305

306

307

308

309

310

311

312

313

314

315

316

317

318

319

320

321

322

323

324

325

\section{DISCUSSION}

\subsection{Self-assemblies of fulvic acid and DTAC}

Over the years, many studies have reported a variety of molecular structures adopted by humic and fulvic acids under various conditions of $\mathrm{pH}$, background electrolyte, and coagulant concentration. Using TEM, Baalousha et al. [15] and Wilkinson et al. [47][48] evidenced networks of fibrils and globules ranging in size from 50 to $300 \mathrm{~nm}$. Above a $1 \mathrm{gC} / \mathrm{L}$ in humic concentration, Myneni et al. [49], using X-ray microscopy, found globules, ring-like, sheet-like, and thread-like structures in the 200-1200 nm size range, by varying the $\mathrm{pH}$, ionic strength of the solution, and nature of the counterion. Using the same technique, Sieliechi et al. [20] also observed the formation of $80 \mathrm{~nm}$ globules during the coagulation of a $10 \mathrm{mgC} / \mathrm{L}$ aquagenic humic acid in presence of hydrolyzed-Fe species. Maurice and Namjesnik-Dejanovic [50], Plaschke et al. [51], used Atomic Force Microscopy to image fulvic and humic acid adsorbed on the basal plane of a freshly cleaved muscovite. Spongy-like structures consisting of $15 \mathrm{~nm}$ rings along with 10-50 nm spheres were found at low humic concentration, whereas aggregates of spheres, chain-like assemblies, and torus-like structures, were obtained at higher concentration. Thieme and Niemeyer [52] investigated by X-ray microscopy an experimental system very similar to ours, i.e. a $10 \mathrm{~g} / \mathrm{L}$ soil humic acid suspension coagulated with various amounts of either Dodecyltrimethylammonium bromide (DTAB) or Hexadecyltrimethylammonium bromide (CTAB). In presence of low DTAB amounts, nearly monodispersed spheres $(224 \mathrm{~nm})$ were observed; those spheres doubled in size with increasing surfactant concentration. At high DTAB concentration, spongy 
networks were obtained. In the case of CTAB additions, micron size hollow spheres with about $240 \mathrm{~nm}$ thick walls were detected at low surfactant concentration.

Many of the molecular structures described in the literature are reminiscent of those found in this study. However, the formation of small unilamellar vesicles was, to our knowledge, never reported for either fulvic or humic colloids. In systems involving a cationic surfactant and an oppositely charged component, vesicles have been found to form either with an anionic surfactant, i.e. a catanionic system [53], or an anionic polymer [54]. Therefore, the observation of vesicles in the mixture SRFA/DTAC is not in itself an argument for either view - supramolecular or polymeric - of SRFA. However, the sequence of molecular structures in which our vesicles are successively found, i.e. SRFA-rich vesicles, globules, disks, DTAC-rich vesicles, is fully consistent with phase diagrams typically encountered in catanionic systems [55][56]. The presence of two DTAC concentration domains with disperse vesicles on both sides of neutral aggregated globules at both $20 \mathrm{mg} / \mathrm{L}$ and $1 \mathrm{~g} / \mathrm{L}$, is also reminiscent of such phase diagrams. Moreover, the morphology of spongy networks observed in association with vesicles bears a close resemblance to that of the branched wormlike micelles found in aqueous surfactants solutions [57].

The amphiphilic character of humic substances has long been recognized [8][9]. According to Wershaw [3], such property is even intrinsic to the formation of HS by enzymatic degradation of plant biopolymers. Recent NMR spectroscopy studies have revealed the existence of more or less flexible alkyl segments in humic substances [58][59][60]. DOSY experiments performed on soil HS even indicated that the diffusion 
coefficients of aliphatic components are consistent with the presence of monomers to tetramers of $\mathrm{C}_{16}-\mathrm{C}_{18}$ fatty ester units [10]. Electrospray ionization also suggested that fulvic acid consists of more or less saturated carbon skeleton with carboxylate functional groups or even lipids [61][62][63]. Therefore, it does not seem unreasonable to consider SRFA as a supramolecular assembly of various anionic amphiphile molecules and the SRFA/DTAC complexes as resulting from a catanionic surfactant system.

357

\subsection{Towards average geometric characteristics of SRFA constituents}

The nature of a self-assembly is essentially controlled by both electrostatic and geometric packing effects. According to the framework introduced by Israelachvili et al. [64], the self-organization of amphiphiles can be reasonably predicted from the critical packing parameter $P$ defined as the ratio between the volume $v_{c}$ of the hydrophobic tail and the product of the polar head surface area $\mathrm{a}_{\mathrm{o}}$ with the critical chain length $l_{c}$ of the surfactant:

$$
P=\frac{v_{c}}{a_{o} l_{c}}
$$

Thus, for cone shaped surfactants, i.e. $\mathrm{p} \leq 1 / 3$, spherical micelles are formed, whereas for cuplike amphiphile molecules, i.e. $1 / 2<\mathrm{p}<1$, vesicles are formed. Bilayers are obtained when the packing parameter is equal to 1. For DTAC, according to the experimental values of geometrical parameters reported in the literature, $v_{D T A C}=0.482$ $\mathrm{nm}^{3}, l_{\text {DTAC }}=1.643 \mathrm{~nm}, a_{\text {DTAC }}=0.88 \mathrm{~nm}^{2}$, p $_{\text {DTAC }} \sim 0.33$ and DTAC therefore forms spherical micelles [36]. 
373 To carry out that kind of calculation for SRFA amphiphiles is more questionable. Even

374 though a micelle-like organization for HS has previously been proposed in the literature

$375[8][9][74]$, a pure hydrophobic interior is highly unlikely in view of the electrokinetic

376 behaviour of SRFA/DTAC complexes at low surfactant concentration (fig. 3a).

377 Furthermore, the polydisperse distribution of molecular weights and a likely variety in

378 the nature of polar head groups, can only lead to a broad estimate of the geometrical

379 characteristics of SRFA amphiphiles. Still, an average polar head area of SRFA can be

380 obtained from surface tension measurements (fig. S4) using Gibbs adsorption equation

381 at the maximal value of $d \gamma / d \operatorname{lnC}[65]$ :

382

$$
a_{S R F A}=\frac{1}{\max N} \text { and } \max _{\max }=\frac{1}{R T} \frac{d}{d \ln C}
$$

where $\Gamma_{\max }$ is the maximal surface adsorption of SRFA, $\mathrm{N}$ Avogadro number, $\mathrm{R}$ the ideal gas constant, $\mathrm{T}$ the absolute temperature, $\gamma$ the surface tension, and $\mathrm{C}$ the SRFA concentration. In our case, $\Gamma_{\max }=2.3510^{-10} \mathrm{~mol} / \mathrm{cm}^{2}$ and hence $a_{S R F A}=0.71 \mathrm{~nm}^{2}$, which is consistent with previous results in the literature [66]. An average chain volume $V_{S R F A}$ of SRFA constituents can also be assessed by assuming a spherical micelle organization: knowing that the volume $\mathrm{V}$ of the micelle is $\mathrm{V}=\mathrm{n} v_{\text {SRFA }}=4 / 3 \pi r_{\text {SRFA }}{ }^{3}$ and the surface $S$ of the micelle is $S=n a_{S R F A}=4 \pi r_{S R F A}{ }^{2}$, with $n$ the number of SRFA constituents in a micelle, $v_{S R F A}=\frac{a_{S R F A} r_{S R F A}}{3}$. Using the average radius-of-gyration $r_{S R F A}$ of $7.5 \AA$ reported in the literature for SRFA [44][67], we obtained $v_{\text {SRFA }}=0.177 \mathrm{~nm}^{3}$. An estimate of the number $n_{c}$ of alkyl groups in the hydrophobic portion of SRFA constituents can also be inferred using the following expression: $v_{S R F A}=\left(27.4+26.9 \mathrm{n}_{\mathrm{c}}\right)$ $\mathrm{x} 10^{-3} \mathrm{~nm}^{3}$ [68]. Interestingly, the $\mathrm{n}_{\mathrm{c}}$ value of about 5 thus obtained, is consistent with 
the picture of short-chained or highly branched aliphatic structures provided by NMR studies of SRFA [69].

The complex formed from DTAC and SRFA constituents possesses its own packing parameter $\mathrm{p}_{\mathrm{c}}$. Following Manohar and Narayanan approach [70], it is convenient to consider two cases: (i) the anionic surfactants ( $\mathrm{N}_{1}$ moles), i.e. the SRFA constituents, are in excess and all the cationic surfactants $\left(\mathrm{N}_{2}\right.$ moles $)$ are complexed; the average packing parameter $\mathrm{P} \quad$ is then: $\quad P=\frac{2 N_{2}}{N_{1}+N_{2}} p_{c}+\frac{N_{1}-N_{2}}{N_{1}+N_{2}} p_{S R F A} \quad$ or $P=2 x p_{c}+(1 \quad 2 x) p_{S R F A}$ where $x=\frac{N_{2}}{N_{1}+N_{2}}$ is the mole fraction of cationic surfactant.

(ii) The cationic surfactants are in excess and all the SRFA constituents are complexed,

$$
P=\frac{2 N_{1}}{N_{1}+N_{2}} p_{c}+\frac{N_{2} N_{1}}{N_{2}+N_{1}} p_{D T A C} \text { or } P=2\left(\begin{array}{lll}
1 & x
\end{array}\right) p_{c}+\left(\begin{array}{ll}
2 x & 1
\end{array}\right) p_{D T A C}
$$

This simple analysis readily accounts for the variety of aggregate structures (micelles, vesicles, disks) that were found in the SRFA/DTAC system, $\mathrm{P}$ changing with the molar fraction of cationic surfactant. Actually, both anionic and cationic surfactants should be distributed between the bulk and the self-assemblies, which complicate the exact calculation of the packing parameter. At the moment, not knowing the amount of DTAC associated in any self-assembly, it is not possible to infer the architectural characteristics of the SRFA/DTAC complex from the geometrical constraints associated with the formation of a given molecular structure. The polar head of the complex may however be determined using the Gibbs adsorption equation, i.e. $\mathrm{a}_{\mathrm{c}} \sim 0.17 \mathrm{~nm}^{2}$ (fig. 4). In addition, the thin thickness of vesicles, less than $1.15 \mathrm{~nm}$ according to the width of 
417 the dark rim on the micrographs (fig. $6 \mathrm{~b} 2$ and $6 \mathrm{f} 2$ ), and hence much less than $l_{D T A C}=$ $418 \quad 1.643 \mathrm{~nm}$, suggests (i) a mismatch in size between the cationic surfactant and the SRFA constituent, and (ii) a deformation of the DTAC hydrocarbon chain around the SRFA constituent.

421

422

\section{Conclusions}

423 The surface active behaviour of complexes formed during the interaction of SRFA with 424 DTAC, the sequence of molecular structures observed by cryoTEM, and the size of constituents involved in those molecular structures, concur to describe SRFA as a supramolecular assembly of amphiphiles molecules. Taking into account the variety of 427 functional groups evidenced in humic material [6], and the various compounds detected in SRFA by coupling solvent extraction with ESI FTICR MS [63], it seems a bit simplistic to assimilate SRFA to a single type of amphiphile molecule, and hence to consider the SRFA/DTAC mixture as a well-defined binary system. In addition, it is highly plausible that only part of SRFA constituents participate to the molecular structures observed here. Nevertheless, such comments do not fundamentally challenge the picture of SRFA as a supramolecular structure. To assess the dynamics of such molecular aggregate, i.e. its formation and evolution in the natural environment, or its relationships to the other DOM components, in particular humic acid, appear to be key elements for a better understanding of global carbon cycle. 


\section{Acknowledgments}

442 AAC gratefully acknowledges the $\mathrm{PhD}$ fellowship granted from the Azm \& Saade 443 Association (Lebanon). AAC, BSL and CPC would also like to thank Stephanie Balor 444 and Vanessa Soldan from the METI Platform.

\section{References}

[1] F. J. Stevenson, Humus chemistry: genesis, composition, reactions. John Wiley \& Sons, 1994.

[2] M. H. B. Hayes, Humic substances II: in search of structure. J. Wiley, 1989.

[3] R. L. Wershaw, "Molecular aggregation of humic substances," Soil Sci., vol. 164, no. 11 , pp. 803-813, 1999.

[4] J. Burdon, "Are the traditional concepts of the structures of humic substances realistic?," Soil Sci., vol. 166, no. 11, pp. 752-769, 2001.

[5] P. MacCarthy, "The principles of humic substances," Soil Sci., vol. 166, no. 11, pp. 738-751, 2001.

[6] R. Sutton and G. Sposito, "Molecular structure in soil humic substances: the new view," Environ. Sci. Technol., vol. 39, no. 23, pp. 9009-9015, 2005.

[7] A. Nebbioso and A. Piccolo, "Advances in humeomics: Enhanced structural identification of humic molecules after size fractionation of a soil humic acid," Anal. Chim. Acta, vol. 720, pp. 77-90, 2012.

[8] R. Von Wandruszka, "The micellar model of humic acid: Evidence from pyrene fluorescence measurements," Soil Sci., vol. 163, no. 12, pp. 921-930, 1998.

[9] T. Guetzloff and J. Rice, "Does Humic-Acid Form a Micelle," Sci. Total Environ., vol. 152, no. 1, pp. 31-35, Jul. 1994. 
464 [10] A. J. Simpson, W. L. Kingery, M. H. B. Hayes, M. Spraul, E. Humpfer, P. 465 Dvortsak, R. Kerssebaum, M. Godejohann, and M. Hofmann, "Molecular

466

467 structures and associations of humic substances in the terrestrial environment," Naturwissenschaften, vol. 89, no. 2, pp. 84-88, Feb. 2002.

[11] N. E. Palmer and R. von Wandruszka, "Dynamic light scattering measurements of particle size development in aqueous humic materials," Fresenius J. Anal. Chem., vol. 371, no. 7, pp. 951-954, 2001.

[12] J. R. Lead, E. Balnois, M. Hosse, R. Menghetti, and K. J. Wilkinson, "Characterization of Norwegian natural organic matter: Size, diffusion coefficients, and electrophoretic mobilities," Environ. Int., vol. 25, no. 2-3, pp. 245-258, Apr. 1999.

[13] E. Balnois, K. J. Wilkinson, J. R. Lead, and J. Buffle, “Atomic force microscopy of humic substances: effects of $\mathrm{pH}$ and ionic strength," Environ. Sci. Technol., vol. 33, no. 21, pp. 3911-3917, 1999.

[14] P. K. Pranzas, R. Willumeit, R. Gehrke, J. Thieme, and A. Knochel, "Characterisation of structure and aggregation processes of aquatic humic substances using small-angle scattering and X-ray microscopy," Anal. Bioanal. Chem., vol. 376, no. 5, pp. 618-625, Jul. 2003.

[15] M. Baalousha, M. Motelica-Heino, S. Galaup, and P. Le Coustumer, "Supramolecular structure of humic acids by TEM with improved sample preparation and staining," Microsc. Res. Tech., vol. 66, no. 6, pp. 299-306, Apr. 2005. 
[16] H. T. Glaser and J. K. Edzwald, "Coagulation and direct filtration of humic substances with polyethylenimine," Environ. Sci. Technol., vol. 13, no. 3, pp. 299$305,1979$.

[17] A. Piccolo, P. Conte, R. Spaccini, and M. Chiarella, "Effects of some dicarboxylic acids on the association of dissolved humic substances," Biol. Fertil. Soils, vol. 37, no. 4, pp. 255-259, Apr. 2003.

[18] M. J. Avena, A. W. P. Vermeer, and L. K. Koopal, "Volume and structure of humic acids studied by viscometry: pH and electrolyte concentration effects," Colloids Surf. Physicochem. Eng. Asp., vol. 151, no. 1-2, pp. 213-224, Jun. 1999.

[19] V. Kazpard, B. S. Lartiges, C. Frochot, J. B. d'Espinose de la Caillerie, M. L. Viriot, J. M. Portal, T. Görner, and J. L. Bersillon, "Fate of coagulant species and conformational effects during the aggregation of a model of a humic substance with Al13 polycations,” Water Res., vol. 40, no. 10, pp. 1965-1974, Jun. 2006.

[20] J.-M. Sieliechi, B. S. Lartiges, G. J. Kayem, S. Hupont, C. Frochot, J. Thieme, J. Ghanbaja, J. B. d'Espinose de la Caillerie, O. Barres, R. Kamga, P. Levitz, and L. J. Michot, "Changes in humic acid conformation during coagulation with ferric chloride: Implications for drinking water treatment," Water Res., vol. 42, no. 8-9, pp. 2111-2123, Apr. 2008.

[21] J. F. Duval, K. J. Wilkinson, H. P. Van Leeuwen, and J. Buffle, "Humic substances are soft and permeable: evidence from their electrophoretic mobilities," Environ. Sci. Technol., vol. 39, no. 17, pp. 6435-6445, 2005.

[22] R. S. Swift, "Macromolecular properties of soil humic substances: fact, fiction, and opinion," Soil Sci., vol. 164, no. 11, pp. 790-802, 1999. 
[23] K. Ghosh and M. Schnitzer, "Macromolecular structures of humic substances.," Soil Sci., vol. 129, no. 5, pp. 266-276, 1980.

[24] J. W. Pavlik and E. M. Perdue, "Number-Average Molecular Weights of Natural Organic Matter, Hydrophobic Acids, and Transphilic Acids from the Suwannee River, Georgia, as Determined Using Vapor Pressure Osmometry," Environ. Eng. Sci., vol. 32, no. 1, pp. 23-30, Jan. 2015.

[25] A. Piccolo, "The supramolecular structure of humic substances," Soil Sci., vol. 166, no. 11, pp. 810-832, 2001.

[26] C. W. Carter and I. H. Suffet, "Binding of DDT to dissolved humic materials," Environ. Sci. Technol., vol. 16, no. 11, pp. 735-740, Nov. 1982.

[27] R. Baigorri, M. Fuentes, G. Gonzalez-Gaitano, and J. M. Garcia-Mina, "Simultaneous presence of diverse molecular patterns in humic substances in solution,” J. Phys. Chem. B, vol. 111, no. 35, pp. 10577-10582, Sep. 2007.

[28] E. Tombácz, K. Varga, and F. Szántó, “An X-ray diffraction study of alkylammonium humate complexes," Colloid Polym. Sci., vol. 266, no. 8, pp. 734$738,1988$.

[29] C. Shang and J. A. Rice, "Investigation of humate-cetyltrimethylammonium complexes by small-angle X-ray scattering," J. Colloid Interface Sci., vol. 305, no. 1, pp. 57-61, Jan. 2007.

[30] A. F. Adou, V. S. Muhandiki, Y. Shimizu, and S. Matsui, "A new economical method to remove humic substances in water: adsorption onto a recycled polymeric material with surfactant addition," Water Sci. Technol. J. Int. Assoc. Water Pollut. Res., vol. 43, no. 11, pp. 1-7, 2001. 
[31] L. K. Koopal, T. P. Goloub, and T. A. Davis, "Binding of ionic surfactants to purified humic acid," J. Colloid Interface Sci., vol. 275, no. 2, pp. 360-367, Jul. 2004.

[32] C. Gamboa and A. F. Olea, "Association of cationic surfactants to humic acid: Effect on the surface activity," Colloids Surf. Physicochem. Eng. Asp., vol. 278, no. 1-3, pp. 241-245, avril 2006.

[33] M. Ishiguro, W. Tan, and L. K. Koopal, "Binding of cationic surfactants to humic substances," Colloids Surf. Physicochem. Eng. Asp., vol. 306, no. 1, pp. 29-39, 2007.

[34] R. C. Averett, J. A. Leenheer, D. M. McKnight, and K. A. Thorn, "Humic substances in the Suwannee River, Georgia; interactions, properties, and proposed structures," United States Geological Survey, WSP - 2373, 1994.

[35] A. Laschewsky, L. Wattebled, M. Arotçaréna, J.-L. Habib-Jiwan, and R. H. Rakotoaly, "Synthesis and Properties of Cationic Oligomeric Surfactants," Langmuir, vol. 21, no. 16, pp. 7170-7179, Aug. 2005.

[36] S. Prévost, L. Wattebled, A. Laschewsky, and M. Gradzielski, "Formation of Monodisperse Charged Vesicles in Mixtures of Cationic Gemini Surfactants and Anionic SDS," Langmuir, vol. 27, no. 2, pp. 582-591, Jan. 2011.

[37] T.-M. Perger and M. Bešter-Rogač, "Thermodynamics of micelle formation of alkyltrimethylammonium chlorides from high performance electric conductivity measurements," J. Colloid Interface Sci., vol. 313, no. 1, pp. 288-295, Sep. 2007.

[38] G. Frappier, B. S. Lartiges, and S. Skali-Lami, "Floc Cohesive Force in Reversible Aggregation: A Couette Laminar Flow Investigation,” Langmuir, vol. 26, no. 13, pp. 10475-10488, Jul. 2010. 
[39] J. D. Ritchie and E. M. Perdue, "Proton-binding study of standard and reference fulvic acids, humic acids, and natural organic matter," Geochim. Cosmochim. Acta, vol. 67, no. 1, pp. 85-96, Jan. 2003.

[40] Y. Takata, H. Tagashira, A. Hyono, and H. Ohshima, "Effect of Counterion and Configurational Entropy on the Surface Tension of Aqueous Solutions of Ionic Surfactant and Electrolyte Mixtures," Entropy, vol. 12, no. 4, pp. 983-995, Apr. 2010.

[41] K. T. Nguyen, T. D. Nguyen, and A. V. Nguyen, "Strong Cooperative Effect of Oppositely Charged Surfactant Mixtures on Their Adsorption and Packing at the Air-Water Interface and Interfacial Water Structure," Langmuir, vol. 30, no. 24, pp. 7047-7051, Jun. 2014.

[42] R. Osterberg and K. Mortensen, "Fractal Dimension of Humic Acids - a SmallAngle Neutron-Scattering Study," Eur. Biophys. J. Biophys. Lett., vol. 21, no. 3, pp. 163-167, Jul. 1992.

[43] R. L. Wershaw and D. J. Pinckney, The Fractionation of Humic acids from Natural Water Systems, vol. 1. In: Journal of research of the U.S. Geological Survey. pp. 361-366, 1973.

[44] G. R. Aiken, P. A. Brown, T. I. Noyes, and D. J. Pinckney, "Molecular Size and Weight of Fulvic and Humic Acids from the Suwannee River," In: Humic substances in the Suwannee River, Georgia; interactions, properties, and proposed structures. p. 89-98, United States Geological Survey, WSP - 2373, 1994.

[45] R. Osterberg and K. Mortensen, "The Growth of Fractal Humic Acids - Cluster Correlation and Gel Formation," Radiat. Environ. Biophys., vol. 33, no. 3, pp. 269-276, Jul. 1994. 
[46] J. Lee, A. Saha, S. M. Pancera, A. Kempter, J. Rieger, A. Bose, and A. Tripathi, "Shear free and blotless cryo-TEM imaging: a new method for probing early evolution of nanostructures," Langmuir ACS J. Surf. Colloids, vol. 28, no. 9, pp. 4043-4046, Mar. 2012.

[47] K. J. Wilkinson, J.-C. Negre, and J. Buffle, "Coagulation of colloidal material in surface waters: the role of natural organic matter," J. Contam. Hydrol., vol. 26, no. 1, pp. 229-243, 1997.

[48] K. J. Wilkinson, E. Balnois, G. G. Leppard, and J. Buffle, "Characteristic features of the major components of freshwater colloidal organic matter revealed by transmission electron and atomic force microscopy," Colloids Surf. Physicochem. Eng. Asp., vol. 155, no. 2-3, pp. 287-310, Sep. 1999.

[49] S. C. B. Myneni, J. T. Brown, G. A. Martinez, and W. Meyer-Ilse, "Imaging of humic substance macromolecular structures in water and soils," Science, vol. 286, no. 5443 , pp. $1335-1337,1999$.

[50] K. Namjesnik-Dejanovic and P. A. Maurice, "Atomic force microscopy of soil and stream fulvic acids," Colloids Surf. Physicochem. Eng. Asp., vol. 120, no. 1, pp. 77-86, 1997.

[51] M. Plaschke, J. Römer, R. Klenze, and J. I. Kim, "In situ AFM study of sorbed humic acid colloids at different pH," Colloids Surf. Physicochem. Eng. Asp., vol. 160, no. 3, pp. 269-279, 1999.

[52] J. Thieme and J. Niemeyer, "Interaction of colloidal soil particles, humic substances and cationic detergents studied by X-ray microscopy," in Structure, Dynamics and Properties of Disperse Colloidal Systems, Springer, 1998, pp. 193201. 
604

605

606

607

608

609

610

611

612

613

614

615

616

617

618

619

620

621

622

623

624

625

626

627

[53] S. Segota and D. Tezak, "Spontaneous formation of vesicles," Adv. Colloid Interface Sci., vol. 121, no. 1, pp. 51-75, 2006.

[54] D. Langevin, "Complexation of oppositely charged polyelectrolytes and surfactants in aqueous solutions. A review," Adv. Colloid Interface Sci., vol. 147, pp. 170-177, 2009.

[55] E. F. Marques, O. Regev, A. Khan, M. da Graça Miguel, and B. Lindman, "Vesicle Formation and General Phase Behavior in the Catanionic Mixture SDS-DDAB-Water. The Cationic-Rich Side," J. Phys. Chem. B, vol. 103, no. 39, pp. 8353-8363, Sep. 1999.

[56] E. F. Marques, O. Regev, A. Khan, M. da Graca Miguel, and B. Lindman, "Vesicle formation and general phase behavior in the catanionic mixture SDSDDAB-water. The anionic-rich side," J. Phys. Chem. B, vol. 102, no. 35, pp. 6746-6758, 1998.

[57] M. Tang and W. C. Carter, "Branching Mechanisms in Surfactant Micellar Growth,” J. Phys. Chem. B, vol. 117, no. 10, pp. 2898-2905, Mar. 2013.

[58] Y.-Y. Chien and W. F. Bleam, "Two-Dimensional NOESY Nuclear Magnetic Resonance Study of pH-Dependent Changes in Humic Acid Conformation in Aqueous Solution,” Environ. Sci. Technol., vol. 32, no. 23, pp. 3653-3658, Dec. 1998.

[59] R. L. Cook and C. H. Langford, "Structural Characterization of a Fulvic Acid and a Humic Acid Using Solid-State Ramp-CP-MAS 13C Nuclear Magnetic Resonance,” Environ. Sci. Technol., vol. 32, no. 5, pp. 719-725, Mar. 1998.

[60] M. Khalaf, S. D. Kohl, E. Klumpp, J. A. Rice, and E. Tombácz, “Comparison of Sorption Domains in Molecular Weight Fractions of a Soil Humic Acid Using 
Solid-State 19F NMR,” Environ. Sci. Technol., vol. 37, no. 13, pp. 2855-2860, Jul.

629

630

631

632

633

634

635

636

637

638

639

640

641

642

643

644

645

646

647

648

649

650 2003.

[61] J. A. Leenheer, R. L. Wershaw, G. K. Brown, and M. M. Reddy, “Characterization and diagenesis of strong-acid carboxyl groups in humic substances," Appl. Geochem., vol. 18, no. 3, pp. 471-482, Mar. 2003.

[62] T. Reemtsma, A. These, A. Springer, and M. Linscheid, "Fulvic acids as transition state of organic matter: indications from high resolution mass spectrometry," Environ. Sci. Technol., vol. 40, no. 19, pp. 5839-5845, 2006.

[63] M. M. Tfaily, R. K. Chu, N. Tolić, K. M. Roscioli, C. R. Anderton, L. Paša-Tolić, E. W. Robinson, and N. J. Hess, “Advanced Solvent Based Methods for Molecular Characterization of Soil Organic Matter by High-Resolution Mass Spectrometry," Anal. Chem., vol. 87, no. 10, pp. 5206-5215, May 2015.

[64] J. N. Israelachvili, D. J. Mitchell, and B. W. Ninham, “Theory of self-assembly of hydrocarbon amphiphiles into micelles and bilayers," J Chem Soc Faraday Trans 2, vol. 72, pp. 1525-1568, 1976.

[65] Y. Chen and M. Schnitzer, "The surface tension of aqueous solutions of soil humic substances.," Soil Sci., vol. 125, no. 1, pp. 7-15, 1978.

[66] I. Taraniuk, E. R. Graber, A. Kostinski, and Y. Rudich, "Surfactant properties of atmospheric and model humic-like substances (HULIS)," Geophys. Res. Lett., vol. 34, no. 16, p. L16807, Aug. 2007.

[67] J. R. Lead, K. J. Wilkinson, E. Balnois, B. J. Cutak, C. K. Larive, S. Assemi, and R. Beckett, "Diffusion Coefficients and Polydispersities of the Suwannee River Fulvic Acid: Comparison of Fluorescence Correlation Spectroscopy, Pulsed-Field 
Gradient Nuclear Magnetic Resonance, and Flow Field-Flow Fractionation," Environ. Sci. Technol., vol. 34, no. 16, pp. 3508-3513, 2000.

[68] C. Tanford, "Micelle shape and size," J. Phys. Chem., vol. 76, no. 21, pp. 30203024, 1972.

[69] K. A. Thorn, "Structural characteristics of the IHSS Suwannee River fulvic and humic acids determined by solution state C-13 NMR spectroscopy," Sci. Total Environ., vol. 62, pp. 175-183, 1987.

[70] C. Manohar and J. Narayanan, “Average packing factor approach for designing micelles, vesicles and gel phases in mixed surfactant systems," Colloids Surf. Physicochem. Eng. Asp., vol. 403, pp. 129-132, 2012.

[71] A. Piccolo, S. Nardi, and G. Cancheri, "Macromolecular changes of soil humic substances induced by interactions with organic acids", Eur. J. Soil Sci., vol. 47, pp. 319-328, 1996.

[72] A. Piccolo, S. Nardi, and G. Cancheri, "Micelle-like conformation of humic substances as revealed by size-exclusion chromatography", Chemosphere, vol. 33, pp. 595-600, 1996.

[73] A. Piccolo, P. Conte, and A. Cozzolino, "Effects of mineral and monocarboxylic acids on the molecular association of dissolved humic substances", Eur. J. Soil Sci., vol. 50, pp. 687-694, 2000.

[74] D. Smejkalova and A. Piccolo, "Aggregation and Disaggregation of humic supramolecular assemblies by NMR Diffusion Ordered Spectroscopy (DOSYNMR), Environ. Sci. Technol., vol. 42, pp. 699-706, 2008. 


\section{Figure captions}

675

676 Figure 1. (a) Typical turbidity curves of SRFA/DTAC suspensions as a function of time 677 for various DTAC additions; SRFA concentration $=20 \mathrm{mg} / \mathrm{L}$.

678

679 Figure 2. Interaction of SRFA with DTAC $\left({ }^{\bullet}\right)$, OTAC $\left({ }^{\bullet}\right)$, and $\mathrm{NaCl}\left({ }^{\bullet}\right)$ as a function of 680 salt concentration: (a) Turbidity curves; (b) Conductivity curves.

681

682 Figure 3. (a) Electrophoretic mobility of SRFA/DTAC complexes versus DTAC 683 concentration $(\bullet)$; (b) Number-average particle size of SRFA/DTAC complexes (DLS) versus DTAC concentration $(\bullet)$ for a SRFA concentration of $20 \mathrm{mg} / \mathrm{L}$. The turbidity curve $\left(^{\bullet}\right)$ is superimposed for comparison. The inset shows the bimodal size distribution obtained for a DTAC addition of $0.19 \mathrm{mmol} / \mathrm{L}$.

687

Figure 4. Surface tension of SRFA/DTAC suspensions versus DTAC concentration $(\bullet)$ for a SRFA concentration of $20 \mathrm{mg} / \mathrm{L}$. The turbidity curve $\left(^{\bullet}\right)$ for a SRFA concentration of $20 \mathrm{mg} / \mathrm{L}$ is shown in order to position the main variations of surface tension.

691

692 Figure 5. CryoTEM micrographs of SRFA in the presence of DTAC concentrations of

$6931.8 \mathrm{mmol} / \mathrm{L}$ and $7.58 \mathrm{mmol} / \mathrm{L}$ (red dots) showing spongy networks and vesicles. The 694 arrows indicate the walls of the vesicles. SRFA concentration $=20 \mathrm{mg} / \mathrm{L}$. 
695 Figure 6. CryoTEM microgographs of SRFA/DTAC molecular structures; all scale bars 696 equal $100 \mathrm{~nm}$ unless otherwise indicated. (a) [DTAC] $=0 \mathrm{mmol} / \mathrm{L}$. (b1-4) [DTAC] $=$ $6977.610^{-3} \mathrm{mmol} / \mathrm{L}$; the arrow indicates an open vesicle. (c) $[\mathrm{DTAC}]=30.210^{-3} \mathrm{mmol} / \mathrm{L}$. 698 (d) $[$ DTAC $]=56.710^{-3} \mathrm{mmol} / \mathrm{L} .(\mathrm{e} 1-2)[\mathrm{DTAC}]=75.610^{-3} \mathrm{mmol} / \mathrm{L}$. (f1-4) $[\mathrm{DTAC}]=$ 700

Figure S1. $\mathrm{pH}$ variation of SRFA/DTAC suspensions as a function of DTAC 702 concentration.

703

704

705

Figure S2. CryoTEM micrographs of (a) DTAC stock solution (10g/L or $37.9 \mathrm{mmol} / \mathrm{L})$; 706

(b) DTAC solution at a concentration of $7.610^{-3} \mathrm{mmol} / \mathrm{L}$, i.e. the concentration at which fulvic-rich vesicles are formed.

707

Figure S3. Size histograms of molecular structures viewed by cryoTEM and evolution of mean particle size with DTAC concentration. The DTAC concentration is indicated in the histograms in mmol/L. The histograms in red are associated with the presence of vesicles.

712

Figure S4. Surface tension of SRFA suspensions as a function of SRFA concentration. 